\title{
Journal of Dermatology and Skin Biology
}

\section{Food Allergy in Atopic Dermatitis}

\section{Arnaldo Cantani}

Department of Pediatrics, Allergy and Clinical Immunology Division, University of Roma "La Sapienza” Medical School.

\section{Received Date: April 2, 2015}

Accepted Date: April 10, 2015

Published Date: April 18, 2015

Corresponding author: Cantani, A. Department of Pediatrics, Allergy and Clinical Immunology Division, University of Roma "La Sapienza” Medical School, Roma. E-mail: acantani13@gmail.com

Citation: Cantani, A. Food allergy in Atopic dermatitis. (2015) J Dermatol Skin Biol 1 (1): 1- 4.

\section{Allergy Today}

Atopic dermatitis (AD) together with asthma and allergic rhinitis represents the most typical manifestation of "atopic constitution". AD was known since ancient times and also Job was probably affected by it. In the Bible (Book of Job) we read:" So went Satan forth from the presence of the Lord and smote Job with sore boils from the sole of his foot unto his crown; and he took him a potsherd to scrape himself withal; and he sat down among the ashes". Davis et al called "Job syndrome" a disease characterized by eczema, severe S. aureus infections, T-lymphocyte deficiency and neutrophils chemotactic abnormalities. Had Job really suffered from the syndrome bearing his name, he had not long survived without an antibiotic treatment. Since his skin affection was highly itching, it is possible that he was afflicted with AD.

Aetius de Amida in $534 \mathrm{BC}$ is to be credited with the first report of a skin affection closely resembling AD. However the first "scientific" description of childhood AD together with advices on its treatment is to be found in the first Textbook of Pediatrics of the western world "Libellus de aegritudinibus infantium", appeared in 1472, written by an Italian medical doctor, Paolo Bagellardo. In 1891 Brocq and Jaquet classified AD as "neurodermatitis". In 1892 Besnier described the illness as "prurigo". He emphasized its chronic and relapsing course beginning in infancy, and stressed the role played by heredity, the common concurrence with asthma and hay-fever, and the characteristic skin lesions. In 1936 Wise and Sulzberger coined the term AD, showing that the condition could be viewed as the "skin analogous of asthma and hay-fever".

\section{Role of Food Allergy in Atopic Dermatitis}

Since 1936 food allergy(FA) was suggested as a contributing factor in AD. It was then shown that CM feeding predisposed to the development of AD since breast fed babies had a prevalence of eczema seven times lower than that of CM-fed babies. Later on, it was reported that children with a family history of allergy and soy formula fed during the first six months of life had less eczema and asthma in comparison with CM-fed children. In a double-blind, crossover study, Atherton et al demon- strated a marked improvement of AD in 21 2-8 yr old children receiving a CM and egg-free diet. It was noted that $14 / 20$ patients responded more favorably to the antigen-avoidance diet employing a soy formula as CM-substitute, whereas only one had a more favorable response to a not CM- and egg-free $\operatorname{diet}^{[1]}$.

The contributing role of both $\mathrm{CM}$ and egg was confirmed by subsequent studies. We have evaluated the efficacy of a $\mathrm{CM}$ and/or egg-free diet in 59 children suffering from severe $\mathrm{AD}^{[2]}$. The elimination of $\mathrm{CM}$ and/or egg for 4 weeks resulted in the healing, or marked improvement of skin lesions in 47/49 children. Sampson ${ }^{[3]}$ has evaluated 210 children in double-blind placebo controlled oral food challenges (DBPCFC): 235(36\%) were positive; 130 children $(62 \%)$ reacted to at least one food. Overall, 174/235 reactions (75\%) involved the skin.

In a recent study of ours, 154 challenge tests were done in 146 children aged 6-10 yrs (median 24mo): 101 with CM, 45 with egg and 8 with other foods. In the 146 children who underwent the challenge test with $\mathrm{CM}$ and/or egg $61(42 \%)$ were positive. 42/101 challenges with CM (42\%) and 19/45 with egg (42\%) were positive. 30/116 children were subjected to both challenge tests (CM and egg). The following symptoms (either immediate or delayed) were elicited by challenge tests: $\mathrm{AD}$ worsening in 30 cases (49\%), Pruritus in 28 (46\%), rash/erythema in $26(43 \%)$, Urticaria in $14(23 \%)$, Asthma in $9(15 \%)$, Lip edema in $5(8 \%)$, Diarrhea in $4(6 \%)$, Vomiting in $2(3 \%)^{[4]}$.

Allergic reactions to $\mathrm{CM}$, egg, and peanut are commonly incriminated in the etiology of AD. In the children studied by Sampson, eggs, peanuts and CM provoked $70 \%$ of the positive DBPCFCs. Less than $15 \%$ of children reacted to more than two foods ${ }^{[3]}$. Employing two foods for challenges, we have obtained a similar percentage of positive reactions $(75 \%)^{[4]}$. It is frequently reported that children with $\mathrm{AD}$ are often allergic to a wide variety of foods. This opinion is generally supported by the high number of positive skin tests and RAST to foods found in children with AD. Although children eat a wide variety of different foods: CM, egg and wheat, which are the most common foods consumed in the Italian diet, and accounted for more than $93 \%$ of the positive responses. These data should be taken into account to eliminate the nutritional problems of too restrictive a diet. Foods frequently reported to induce hypersensitivity such

Copy rights: (C2015 Cantani, A. This is an Open access article distributed under the terms of Creative Commons Attribution 4.0 International License. 
as citrus fruit, chocolate, strawberries ${ }^{[3]}$, did not elicit positive responses in our patents ${ }^{[4]}$.

\section{Natural History of Atopic Dermatitis}

As yet, retrospective and longitudinal studies have been carried out by many authors to assess the significant factors that may affect the $\mathrm{AD}$ outcome. Widely varying estimates ranging from $20-80 \%$ of patient improvement during adolescence and adulthood have been reported, probably due to different selection criteria. However, most studies suggest that adolescents tend to outgrow the disease in a percentage between 40 and $50 \%$. The prevalence of respiratory allergy in AD patients has been evaluated between 30 and $55 \%{ }^{[5]}$.

Recently we have carried out a long-term (5yrs), prospective study on 56 children. AD was due to FA in $82 \%$ of cases, in whom the offending foods were CM and egg in $69 \%$ of children. $43 \%$ of patients still had AD at the last follow-up. Tolerance toward CM and egg was reached at age 4yrs. In addition $50 \%$ of patients had bronchial asthma and/or allergic rhinitis during the follow-up. The following parameters were significantly associated with persisting skin lesions: age of onset of AD after the sixth month of life $(\mathrm{p}<0.05)$; widespread or not typical (reverse pattern) skin lesions $(p<0.005)$; persisting food intolerance $(p<0.005)$. Family history of atopy, sex, total $\operatorname{IgE}$ levels, specific IgE to foods, skin test responses, severity of skin lesions, had no predictive value. Positive skin tests and/or IgE to inhalant allergens at the first examination appeared to have a predictive value for the development of respiratory allergy $(\mathrm{p}<$ $0.025)^{[6]}$.

Ford and Taylor ${ }^{[7]}$ found in 25 young children with AD and egg hypersensitivity, as confirmed by DBFC, and followed up to $2.5 y$ rs that hypersensitivity resolved in 11 children and persisted in 14 .

Although the difference is widely varying between one study and the other, the data suggest that children with FA diagnosed at older ages do not tend to outgrow the illness. As recently reported by Sampson ${ }^{[3]}, 75$ children on avoidance diet were rechallenged after 1-2yrs and 38/121 (31\%) rechallenges were negative. The food(s) eliciting hypersensitivity responses influenced the development of tolerance. For example, $<25 \%$ of reactions to $\mathrm{CM}$, egg, and peanut were lost during the above period, whereas $1 / 2$ of soy sensitivity and $2 / 3$ of other food allergies were outgrown in the same period. In summary, 18/75 (25\%) children lost clinical FA after 1-2yrs, and other 4 lost any evidence of hypersensitivity after an additional $1 \mathrm{yr}$ avoidance diet. Therefore, approximately $1 / 3$ of FA children with AD will outgrow their clinical hypersensitivity in 1-3yrs on condition that they are maintained on an appropriate allergen elimination diet.

The importance and necessity of the elimination of foods inducing clinically documented FA is further demonstrated by the different AD course in children following or not a restricted diet. In a group of 34 children followed prospectively for 3-4yrs, 17 of whom with FA diagnosed with DBPCFC and maintained on a restricted diet (diet group), and 17 either with no FA confirmed or not complying with their restricted diet, it was shown that the diet group fared much better clinically than the non-diet group $(\mathrm{p}<0.001)$. In addition, total serum IgE levels decreased significantly over the study course only in the diet group $(p=0,037)^{[3]}$.

\section{Diagnosis of Food Allergy in Children with Atopic Dermatitis}

Since there are as yet no laboratory tests for the diagnosis of FA which obviate the need for careful clinical assessment, a "diagnostic" oligoantigenic elimination diet should be given for no more than 4 weeks. We use with good results (and infants compliance) a home-made meat diet prepared as suggested by Rezza. One of the major advantages of this diet is that it can be adapted to the individual patient that is vegetables, other types of fruit and meat, wheat flour and other nutrients can be added to the diet according to the age and weight of the child, and the physician's judgment.

When a child shows a clearcut improvement after the 4 week diet, he can undergo a challenge test. The procedure is not risk-free. David ${ }^{[8]}$ reported anaphylactic shock in four children. We also observed in 18 children severe immediate reactions after the challenge test: 9 with $\mathrm{CM}$ and 9 with egg ${ }^{[4]}$.

Many of these immediate reactions may be a consequence of release of mediators. This agrees with the results by Sampson and Jolie ${ }^{[9]}$ about the histamine release after food challenge tests. Although histamine was the only mediator they tested, it is possible that additional mediators released by mast cells are involved. However, since histamine is rapidly cleared in the portal and renal circulation, only a fraction of the histamine released by gut-associated mastcells would reach peripheral sites. It is therefore likely that the histamine so released in a sensitized patient may facilitate the entrance of a greater amount of antigen by inducing a local anaphylaxis. These antigens reach cutaneous mast cells very rapidly, thus inducing a further mediator release. As originally demonstrated by Engman et a ${ }^{[10]}$, the release of various mast cell mediators, including histamine, can provoke severe pruritus, secondary scratching, and subsequent development of eczematous skin lesions. Very recently Fogh et $\mathrm{al}^{[11]}$ have demonstrated that the inflammatory mediators prostaglandin E2 and leukotriene B4 are present in lesional skin of patients with $\mathrm{AD}$ in biologically active concentrations. It is therefore speculated that these mediators may be involved in the biochemical processes leading to $\mathrm{AD}$ since they are able to induce cutaneous inflammation and to modulate cellular immunity.

Among additional factors other than antigen that could promote histamine release, there are the cytokines [histamine releasing factors (HRF)], subsequently identified as capable of activating a host of IgE bearing cells (mast cells, lymphocytes, eosinophils, basophils, monocytes, and platelets). By binding to surface bound IgE molecules and basophils, HRF(s) may perpetuate the histamine release and induce allergic reactions which are too late or too prolonged to be labeled as classic IgE-mediated reactions. The findings that $\mathrm{IgE}$ molecules from atopic patients bind HRF but that IgE molecules from non-atopic subjects do not suggest that these molecules have a great deal of clinical significance. In addition, it has been noted that children with AD and FA whose skin lesions cleared while on allergen avoidance diet exhibited a "spontaneous" HRF in vitro from peripheral blood basophils (SBHR) close to normal. Conversely SBHR was high in non-dieting children. SBHR also appears to correlate with the "spontaneous" HRF generation from peripheral blood mononuclear cells. HRF may activate or lower the activation threshold of basophils and mast cells and could account for both the high SBHR observed in vitro and the increased basophil releasability seen in some AD patients. Taken together, these data suggest that in $\mathrm{AD}$ there exist a vicious circle, by which 
immunologic and non-immunologic factors act in various ways and at differing levels triggering different though synergic reactions to initiate, amplify and maintain the chronic skin lesions characteristic of the condition. It may be hypothesized that also in $\mathrm{AD}$ the allergens could induce a cutaneous hyper reactivity analogous to the bronchial hyper reactivity seen in patients with allergic asthma ${ }^{[12]}$. This could in turn lower the pruritus threshold regarding a wide range of nonspecific stimuli such as irritants, heat, humidity, stress, and the like. Despite this promising scenario, the structures on the IgE molecule recognized by HRF are so far still poorly understood, and the basic underlying defect(s) of $\mathrm{AD}$ remains elusive ${ }^{[13]}$.

\section{Reliability of Skin Tests and Rast in Atopic Dermatitis}

Both diagnosis and treatment are difficult since the much in vogue diagnostic items, ST and RAST yield varying re-sults in term of sensitivity, specificity, predicted positive and negative values. In this regard, a recent work of ours has demonstrated that considering sensitivity, specificity, and positive and negative predictive accuracy of ST and RAST of both CM and egg as regards immediate and total reactions, ST sensitivity is high ( 0.88 for $\mathrm{CM}$ and 1,00 for egg for immediate reactions and 0.88 for $\mathrm{CM}$ and 0,95 for egg for total reactions). However specificity is low $(0,25$ for $\mathrm{CM}$ and 0,27 for egg for immediate reactions and 0.30 for $\mathrm{CM}$ and 0,38 for egg for total reactions). In addition, the ST positive predictive values are low ( 0.15 for $\mathrm{CM}$ and 0,30 for egg for immediate reactions and 0.46 for $\mathrm{CM}$ and 0,60 for egg for total reactions). Since history is unreliable especially as regards the immediate reactions predictivity, challenge tests in children with positive ST should always be done with caution. The ST high negative predictive accuracy ( 0.93 for $\mathrm{CM}$ and 1.00 for egg) permits to exclude immediate reactions following the challenge test. RAST sensitivity is lower than that of ST. RAST specificity is better than ST, however neither can be utilized at the clinical level. In addition RAST negative predictive accuracy is lower than that of ST and consequently scarcely useful for food allergy diagnosis. Its use should be limited to those cases in whom antihistaminic administration cannot be discontinued or dermographism is remarkable or lichenification fails to allow ST evaluation ${ }^{[4]}$. In addition, we have shown that it is impossible to rely on skin test negativity to exclude FA diagnosis, since in 35 children (22 M, $13 \mathrm{~F}$ aged 1-7, median $1,8 \mathrm{mo}$ ) with "borderline" $\mathrm{AD}$ and all with negative prick test for $\mathrm{CM}$, challenge for CM was negative in $28(80 \%)$ and positive in $7(20 \%)$. In addition RAST for CM was positive in $6 / 35$ $(17 \%)$ children, 5 of whom $(83 \%)$ had a negative challenge and $1(17 \%)$ positive, whereas $6 / 29$ children with negative RAST $(21 \%)$ had a positive challenge for $\mathrm{CM}^{[14]}$.

\section{Pharmacological Treatment of Food Allergy in AD}

The treatment of choice of AD due to FA is the elimination of the offending food(s). This can be easily achieved when the child is allergic to foods which are not common items in the diet, such as strawberries, sea foods, citrus fruit, peach, etc., or when the offending food is not an important nutrient, such as apples, nuts, chocolate, etc. Problems arise when the child is allergic to food(s) which are common items in the diet and/or to food(s) which have a high nutritional value (CM, egg, fish).

In these cases, a drug able of preventing symptoms would be useful in order to avoid a strict diet free of such im- portant nutrients. Although SCG has been widely used for the management of respiratory allergy, conflicting re-sults of FA treatment have been reported by several investigators since the first report in which it was shown that SCG pretreatment of a soy allergic patient gave no protection when the drug was inhaled, whereas oral treatment with $400 \mathrm{mg}$ blocked either the immediate or the late reaction.

Twelve papers on the use of SCG in the management of children with AD have been reviewed. These papers included 281 children aged $0.5-15 \mathrm{yrs}^{[15]}$. The analysis of the 12 studies shows that 5 were carried out in the open, 1 in the single blind, 6 in the double blind fashion. Four out of 5 studies in the open fashion yielded positive results, which are SCG was effective in the management of AD. The double blind studies were positive in 3 cases and negative in 3 , the only trial with doubtful results was conducted in the open fashion.

As already reported by previous studies, there are several explanations for conflicting results of SCG in FA. The discrepancy of observations may be dependent upon several factors such as different selection criteria of patients, the wide variations in daily dosage of SCG used by various investigators, the different amount of food antigens ingested by the patients during the trials depending upon the varying diet followed, the diversity in the evaluation of SCG efficacy, and the problems regarding the patient compliance as well. Finally, SCG generally appears to be a safe drug, and the reports of adverse reactions to it are scarce.

\section{Conclusion}

Few illnesses like AD, which although not being lethal are causes of invaluable physical and psychic suffering for children and their parents. The children with AD should be followed and treated with special care. At the very onset of the condition all the necessary therapeutic measures should be started to control the first clinical manifestations. In addition, AD (again like few other diseases) cannot benefit from pre-arranged therapeutic protocols, as stressed by Engman in 1936 "The study of a patient with eczema follows no set rule. Each problem must be dealt with individually" ${ }^{[10]}$. Preventive measures should be instituted in all at risk newborns to lessen the prevalence and/or alleviate the severity of $\mathrm{AD}$, an affection common and seriously invalidating as regards both children and their parents. We want to repeat that "a dollar spent for prevention pays more than a thousand for cures".

\section{References}

1. Businco, L., Cantani, A., Monteleone, A.M., et al. Atopic dermatitis in children: an update. (1988) Folia Allergol Immunol Clin 35: 41-51.

2. Businco, L., Businco, E., Cantani, A., et al. Results of a milk and/or egg free diet in children with atopic dermatitis. (1982) Allergol Immunopahol 10(4): 283-288.

3. Sampson, H. A. The role of immediate hypersensitivity in the pathogenesis of atopic dermatitis. (1989) Allergy 44(9):52-58.

4. Meglio, P., Giampietro, P. G., Farinella, F., et al. Personal experience on the diagnostic procedures in children with atopic dermatitis and food allergy. (1989) Allergy 44(9):165-173.

5. Businco, L., Cantani, A., Benincori, N., et al. State of the art: 
Atopic dermatitis and food allergy. Diagnosis and management. In Vierucci, A., and Immunita and infection in diseases of the liver and gastrointestinal tract in children. (1984) Milan Italy Masson Publishers: 103-116.

6. Businco, L., Ziruolo, M.G., Ferrara, M., et al. Natural history of atopic dermatitis in childhood: An updated review and personal experience of a five-year follow-up. (1989) Allergy 44(9): 70-80. 7. Ford, R.P., Taylor, B. Natural history of egg hypersensitivity. (1982) Arch Dis Child 57(9): 649-652.

8. David, T.J. Anaphylactic shock during elimination diets for severe atopic eczema. (1984) Arch Dis Child 59(10): 983-986.

9. Sampson, H.A., Jolie, P.L. Increased plasma histamine concentrations after food challenges in children with atopic dermatitis. (1984) N Engl J Med 311(6): 372-376.
10. Engman, M. F., Weiss, R. S., Engman, M. F. Eczema and environment. (1936)Med Clin North Am 20: 651-663.

11. Fogh, K., Herlin, T., Kragballe, K. Eicosanoids in skin of patients with atopic dermatitis: Prostaglandin E2 and leukotriene B4 are present in biologically active concentrations. (1989) J Allergy Clin Immunol 83(2 Pt 1): 450-455.

12. Lichtenstein, L. M. Histamine releasing factors and IgE heterogeneity. (1988) J Allergy Clin Immunol 81(5 Pt 1): 814-820. 13. Businco, L., Cantani, A. Recent acquisitions on atopic dermatitis of the child. (1989) not Allergol (in press).

14. Cantani, A., Lucenti, P. Ineffectiveness of prick test negativity to exclude food allergy in children.

15. Businco, L., Cantani, A., Meglio, P., et al. Sodium cromoglycate in the management of food allergy in children. (1989) Food allergy in infancy and childhood: 189-204. 